\title{
Readmissions, revisions, and mortality after treatment for proximal humeral fractures in three large states
}

Dominique I. Dabija ${ }^{1}$, Hongshu Guan ${ }^{2}$, Andrew Neviaser ${ }^{3}$ and Nitin B. Jain ${ }^{4,5^{*}}$ (D)

\begin{abstract}
Background: Proximal humeral fractures can be treated non-operatively or operatively with open reduction and internal fixation (ORIF) and arthroplasty. Our objective was to assess practice patterns for operative and nonoperative treatment of proximal humeral fractures. We also report on complications, readmissions, in-hospital mortality, and need for surgery after initial treatment of proximal humeral fractures in California, Florida, and New York.

Methods: The State Inpatient Databases and State Emergency Department Databases from the Healthcare Cost and Utilization Project, sponsored by the Agency for Healthcare Research and Quality, were used for the states of California (2005-2011), Florida (2005-2014), and New York (2008-2014). Data on patients with proximal humeral fractures was extracted. Patients underwent non-operative or operative (ORIF or arthroplasty) treatment at baseline and were followed for at least 4 years from the index presentation. If the patient needed subsequent surgery, time to event was calculated in days, and Kaplan-Meier survival curves were plotted
\end{abstract}

Results: At the index visit, $90.3 \%$ of patients with proximal humeral fractures had non-operative treatment, 6.7\% had ORIF, and 3.0\% had arthroplasty. $7.6 \%$ of patients initially treated non-operatively, $6.6 \%$ initially treated with ORIF, and $7.2 \%$ initially treated with arthroplasty needed surgery during follow-up. Device complications were the primary reason for readmission in $5.3 \%$ of ORIF patients and $6.7 \%$ of arthroplasty patients $(p<0.0001)$. All-cause in-hospital mortality was $9.8 \%$ for patients managed non-operatively, $8.8 \%$ for ORIF, and $10.0 \%$ for arthroplasty $(p=0.003)$.

Conclusions: A majority of patients with proximal humeral fractures underwent non-operative treatment. There was a relatively high all-cause in-hospital mortality irrespective of treatment. Given the recent debate on operative versus non-operative treatment for proximal humeral fractures, our study provides valuable information on the need for revision surgery after initial treatment. The differences in rates of revision surgery between patients treated non-operatively, with ORIF, and with arthroplasty were small in magnitude. At nine years of follow-up, ORIF had the lowest probability of needing follow-up surgery, and arthroplasty had the highest.

Keywords: Proximal humeral fractures, Open reduction and internal fixation, Arthroplasty

\footnotetext{
* Correspondence: nitin.jain@vanderbilt.edu

${ }^{4}$ Department of Physical Medicine and Rehabilitation, Vanderbilt University

Medical Center, 2201 Children's Way, Suite 1318, Nashville, TN 37212, USA

${ }^{5}$ Department of Orthopaedics and Rehabilitation, Vanderbilt University

Medical Center, Nashville, TN, USA

Full list of author information is available at the end of the article
}

(c) The Author(s). 2019 Open Access This article is distributed under the terms of the Creative Commons Attribution 4.0 International License (http://creativecommons.org/licenses/by/4.0/) which permits unrestricted use, distribution, and reproduction in any medium, provided you give appropriate credit to the original author(s) and the source, provide a link to the Creative Commons license, and indicate if changes were made. The Creative Commons Public Domain Dedication waiver (http://creativecommons.org/publicdomain/zero/1.0/) applies to the data made available in this article, unless otherwise stated. 


\section{Background}

After the age of 50, the incidence of proximal humeral fractures increases before peaking between 80 to 89 years $[1,2]$. Over $90 \%$ of these injuries are the result of a fall. Due to the growing elderly population, the number of fractures between 2008 and 2030 is expected to increase by $50 \%[1,3]$. Treatments for proximal humeral fractures include non-operative care and surgery. Surgical care includes open reduction and internal fixation (ORIF) and arthroplasty [4]. Some studies suggest that operative treatment of complex proximal humeral fractures, particularly in elderly patients, does not lead to a significantly improved outcome for patients as compared with non-operative treatment, and can lead to more complications and revision surgeries [5-9].

Few studies have used national databases to report the epidemiology of upper extremity procedures and specifically for humeral fractures $[1,10]$. One study used state inpatient databases to track readmission rates after proximal humeral fracture for up to 90 days following operative treatments [11]. This study did not report on patients receiving non-operative treatment. To our knowledge, longitudinal data on complications, readmissions, and conversion of non-operative treatment to surgery or ORIF to arthroplasty has not been reported in large state or national datasets for proximal humeral fractures. Given the debate on best treatment approaches for proximal humeral fractures, this data provides insights into current practice patterns and failure of an initial treatment approach (as determined by conversion to a different surgical treatment). The aim of our study was to analyze practice patterns for patients with proximal humeral fractures in the states of California, Florida, and New York. We longitudinally followed patients for at least 4 years to report on complications and revision surgery.

\section{Methods}

\section{Data sources}

Data on patients with proximal humeral fractures was obtained from the Healthcare Cost and Utilization Project (HCUP), sponsored by the Agency for Healthcare Research and Quality (AHRQ) [12]. The State Inpatient Databases (SID) contain all or nearly all inpatient records from participating states [13]. Since patients with proximal humeral fractures may be discharged from the emergency room without being admitted to an in-patient facility, the State Emergency Department Databases (SEDD) that contain records of emergency department visits that do not result in admission were also used [14]. Information was obtained from these databases for patients in California whose index visit was between 2005 and 2007, and their follow-up visits were tracked through 2011 (last year for availability of California data); patients in Florida whose index visit was between 2005 and 2010, and their follow-up visits were tracked through 2014; and patients in New York whose index visit was between 2008 and 2010, and their follow-up visits were tracked through 2014. The states and years chosen were based upon the availability of longitudinal follow-up data to track an individual patient.

\section{Sample selection}

Procedures and diagnoses were identified by coding from the International Classification of Diseases, Ninth Revision, Clinical Modification (ICD-9CM). Index visits were defined by any ICD-9-CM diagnosis code for closed fractures of the proximal humerus: 812.00, $812.01,812.02,812.03$, or 812.09. Patients were excluded if their primary diagnostic code indicated that the surgery at their initial visit was for correction of a previous arthroplasty or complication, or if they had any diagnosis code for malignancies or pathological fractures of the humerus, scapula, or glenoid. Selected patients were then separated into three groups (non-operative, ORIF, and arthroplasty) depending on the treatment they received at their index visit. Any procedure code of 79.31 defined ORIF while 81.80 or 81.81 defined arthroplasty. Patients with a diagnosis code indicating a proximal humeral fracture but without a surgical procedure code were classified as receiving non-operative treatment.

\section{Comorbidities and outcome measures}

Other information extracted from this initial visit included patient comorbidity, which was assessed with the Charlson Index (categorized into 0,1 , and $\geq 2$ ), calculated from discharge diagnoses of the index visit, and modified for administrative data by Deyo $[15,16]$. Disposition on discharge was classified as routine or nonroutine (transfer to short-term hospital, skilled nursing facility, intermediate care facility, another type of facility, or home health care). Complications of the index admission included wound complications, pulmonary embolism, deep venous thrombosis (DVT) of lower extremity, venous embolism of thrombosis of other site, cardiac complications, cardiac rhythm conversion, and unspecified septicemia. The corresponding ICD-9CM diagnosis and procedure codes that were used to ascertain these complications are listed in Additional file 1. All-cause mortality was documented for all patients who died while in the hospital.

\section{Longitudinal follow-up}

Each patient is provided a unique identifier in the databases that allows patients to be tracked over time. Patients were followed longitudinally for at least four years and up to nine years after the index visit to identify hospital readmissions. The primary reason for readmission 
was determined based on ICD-9 codes. The patient was determined to have a subsequent ORIF or arthroplasty if they had a corresponding ICD-9 procedure code at readmission.

\section{Statistical analysis}

Characteristics of the patient population were analyzed as means, medians, standard deviations, and proportions. Chi-square tests and analysis of variance (ANOVA) tests were used to compare the three groups (non-operative, ORIF, and arthroplasty), and $p$-values were reported. Time to event (surgery or revision surgery) was calculated in days, and KaplanMeier survival curves were plotted [17].

\section{Results}

A total of 134,411 patients were treated for a proximal humeral fracture in California (2005-2007), Florida (2005-2010), and New York (2008-2010) (Table 1). A majority of these patients were treated non-operatively (90.3\%) while $6.7 \%$ underwent ORIF and $3.0 \%$ had an arthroplasty at the index visit. The mean age of patients undergoing non-operative treatment was $66 \pm 22$ years, ORIF was $65 \pm 18$ years, and arthroplasty was $74 \pm 12$ years $(p<0.0001)$. Approximately $70 \%$ of patients undergoing non-operative treatment and ORIF were female compared to $77.2 \%$ of those undergoing arthroplasty $(p<0.0001)$. The median length of hospital stay was 0 days for non-operative management, 4 days for ORIF, and 5 days for arthroplasty $(\mathrm{p}<0.0001)$.

Patients undergoing ORIF were significantly more likely to have a wound complication as compared with patients undergoing arthroplasty $(\mathrm{p}<0.0001)$ during their index admission (Table 1). There was also a significant difference in the proportion of patients with cardiac complications between those who received non-operative treatment versus ORIF versus arthroplasty $(0.09 \%$ vs. $0.77 \%$ vs. $1.10 \% ; p=0.0003)$ during their index

Table 1 Baseline Characteristics of Patients with Proximal Humeral Fractures in California, New York, and Florida

\begin{tabular}{|c|c|c|c|c|c|}
\hline & \multirow[b]{2}{*}{$\begin{array}{l}\text { Total } \\
134,411\end{array}$} & \multicolumn{3}{|l|}{ Treatment } & \multirow[b]{2}{*}{$p$-value } \\
\hline & & $\begin{array}{l}\text { Non-Operative } \\
121,411(90.3 \%)\end{array}$ & $\begin{array}{l}\text { ORIF } \\
8994(6.7 \%)\end{array}$ & $\begin{array}{l}\text { Arthroplasty } \\
4006(3.0 \%)\end{array}$ & \\
\hline $\begin{array}{l}\text { Age } \\
\text { Mean } \pm \text { SD; Median }\end{array}$ & $65.8 \pm 21.3 ; 71$ & $65.7 \pm 21.8 ; 71$ & $65.0 \pm 18.3 ; 68$ & $73.5 \pm 11.6 ; 76$ & $<0.0001$ \\
\hline Female & $94,342(70.2 \%)$ & $85,234(70.2 \%)$ & $6014(66.9 \%)$ & 3094 (77.2\%) & $<0.0001$ \\
\hline \multicolumn{6}{|l|}{ Charlson Index: } \\
\hline 0 & 93,182 (69.3\%) & $86,474(71.2 \%)$ & 4847 (53.9\%) & 1861 (46.5\%) & \multirow[t]{3}{*}{$<0.0001$} \\
\hline 1 & 26,901 (20.0\%) & 22,998 (18.9\%) & $2560(28.5 \%)$ & 1343 (33.5\%) & \\
\hline$\geq 2$ & $14,328(10.7 \%)$ & $13,974(11.5 \%)$ & 1587 (17.6\%) & $802(20.0 \%)$ & \\
\hline \multicolumn{6}{|l|}{ Disposition on discharge: } \\
\hline Routine & 99,667 (74.2\%) & $94,643(78.0 \%)$ & $3887(43.2 \%)$ & $1137(28.4 \%)$ & \multirow[t]{2}{*}{$<0.0001$} \\
\hline Non-routine $e^{a}$ & $32,840(24.4 \%)$ & $25,014(20.6 \%)$ & 4995 (55.5\%) & $2831(70.7 \%)$ & \\
\hline $\begin{array}{l}\text { Average hospital length of stay } \\
\text { Mean } \pm \text { SD; Median }\end{array}$ & $2.0 \pm 5.3 ; 0$ & $1.5 \pm 4.8 ; 0$ & $6.1 \pm 7.9 ; 4$ & $6.2 \pm 5.9 ; 5$ & $<0.0001$ \\
\hline $\begin{array}{l}\text { Number of chronic conditions } \\
\text { Mean } \pm \text { SD; Median }\end{array}$ & $2.1 \pm 2.6 ; 1$ & $1.9 \pm 2.5 ; 1$ & $3.8 \pm 2.8 ; 3$ & $4.4 \pm 2.7 ; 4$ & $<0.0001$ \\
\hline Osteoporosis & 8582 (6.4\%) & $6698(5.5 \%)$ & 1163 (12.9\%) & 721 (18.0\%) & $<0.0001$ \\
\hline \multicolumn{6}{|c|}{ Complications during in-hospital stay for index admission } \\
\hline Wound complications & $124(0.09 \%)$ & $\mathrm{N} / \mathrm{A}$ & $31(0.34 \%)$ & * & $<0.0001$ \\
\hline Pulmonary embolism & $221(0.16 \%)$ & $154(0.13 \%)$ & $42(0.47 \%)$ & $25(0.62 \%)$ & 0.06 \\
\hline Deep venous thrombosis of lower extremity & $288(0.21 \%)$ & $225(0.19 \%)$ & $37(0.41 \%)$ & $26(0.65 \%)$ & 0.95 \\
\hline Venous embolism or thrombosis of other site & $140(0.10 \%)$ & $97(0.08 \%)$ & $27(0.30 \%)$ & $16(0.40 \%)$ & 0.11 \\
\hline Cardiac complications & $223(0.17 \%)$ & $110(0.09 \%)$ & $69(0.77 \%)$ & $44(1.10 \%)$ & 0.0003 \\
\hline Cardiac rhythm conversion & $249(0.19 \%)$ & $208(0.17 \%)$ & $25(0.28 \%)$ & $16(0.40 \%)$ & 0.96 \\
\hline Unspecified septicemia & $525(0.39 \%)$ & $458(0.38 \%)$ & $48(0.53 \%)$ & $19(0.47 \%)$ & 0.18 \\
\hline
\end{tabular}

ORIF open reduction and internal fixation

SD standard deviation

* Value $<10$

ח $p$-values of non-operative vs. ORIF vs. arthroplasty as treatment

${ }^{a}$ Non-routine discharges include transfer to short-term hospital, skilled nursing facility, intermediate care facility, another type of facility, or home health care

${ }^{\mathrm{b}}$ Includes data only from FL and NY 
admission (Table 1). All-cause in-hospital mortality was 9.8\% for patients managed with non-operative treatment, $8.8 \%$ for ORIF, and $10.0 \%$ for arthroplasty $(p=0.003$; Table 2).

Of the patients who had non-operative treatment initially, $4.5 \%$ required an ORIF and $3.1 \%$ underwent an arthroplasty during follow-up (Fig. 1a, Table 2). Subsequent arthroplasty was performed in $4.1 \%$ of the patients initially treated with ORIF and $5.4 \%$ of the patients initially treated with arthroplasty (Fig. 1b, c). Device complications were the primary reason for readmission in $5.3 \%$ of ORIF patients and $6.7 \%$ of arthroplasty patients $(p<0.0001)$.

There was variation in the time to readmission between states (Table 3). In California, the mean number of days to readmission for ORIF after initial non-operative treatment was $90.7 \pm 284.3$ days, after initial ORIF was $358.2 \pm 527.5$ days, and after initial arthroplasty was $482.9 \pm 331.7$ days $(p<0.0001)$. In Florida, the mean number of days to readmission for ORIF after initial non-operative treatment was $139.5 \pm 436.0$ days, after initial ORIF was 623.4 \pm 739.2 days, and after initial arthroplasty was $1002.8 \pm 791.5$ days $(p<0.0001)$. In Florida, the mean number of days to readmission for arthroplasty after initial non-operative treatment was $192.9 \pm 455.2$ days, after initial ORIF was $378.6 \pm 523.0$ days, and after initial arthroplasty was 588.2 \pm 628.9 days $(\mathrm{p}<0.0001)$. In New York, the mean number of days to readmission for arthroplasty after initial non-operative treatment was $145.6 \pm 341.6$ days, after initial ORIF was
$294.5 \pm 345.3$ days, and after initial arthroplasty was $568.0 \pm 533.1$ days $(\mathrm{p}<0.0001)$.

\section{Discussion}

We used large statewide in-patient and emergency room databases to assess management of patients with proximal humeral fractures. We also tracked this large cohort of patients in California, Florida, and New York for at least four years and up to nine years from index visit to report on readmissions and complications. We found that $90.3 \%$ of patients underwent non-operative treatment. The incidence of proximal humeral fractures was associated with an all-cause in-hospital mortality of $8.8-$ $10.0 \%$. Among patients undergoing ORIF, 5.3\% of patients, and among those undergoing arthroplasty, $6.7 \%$ of patients required readmission due to device complications. Among patients undergoing initial non-operative treatment, $7.6 \%$ underwent subsequent ORIF or arthroplasty. Among patients undergoing initial ORIF, 6.6\% required a revision ORIF or arthroplasty, and among patients undergoing initial arthroplasty, $7.2 \%$ required revision arthroplasty or ORIF during follow-up. The exact nature of the ORIF following arthroplasty is not known. Overall, arthroplasty had the lowest probability of survival (of procedure) at nine years of follow-up.

Zhang et al. reported that $3.1 \%$ of patients had surgical complications requiring readmissions using the HCUP State Inpatient Database for California (2005-2010), Florida (2005-2010), Hawaii (2006-2007), North Carolina (2006-2010), Nebraska (2006-2010), New York

Table 2 Outcomes of Patients during Follow-Up

\begin{tabular}{|c|c|c|c|c|}
\hline & \multicolumn{3}{|l|}{ Initial Treatment } & \multirow[b]{2}{*}{$p$-value ${ }^{\Pi}$} \\
\hline & $\begin{array}{l}\text { Non-Operative } \\
121,411\end{array}$ & $\begin{array}{l}\text { ORIF } \\
8994\end{array}$ & $\begin{array}{l}\text { Arthroplasty } \\
4006\end{array}$ & \\
\hline \multicolumn{5}{|l|}{ Revision surgery ${ }^{\mathrm{a}}$ : } \\
\hline ORIF & $5410(4.5 \%)$ & $225(2.5 \%)$ & $73(1.8 \%)$ & 0.009 \\
\hline Arthroplasty & $3747(3.1 \%)$ & $369(4.1 \%)$ & $217(5.4 \%)$ & 0.66 \\
\hline All-cause mortality while in-patient & $11,876(9.8 \%)$ & $787(8.8 \%)$ & $401(10.0 \%)$ & 0.003 \\
\hline \multicolumn{5}{|l|}{ Reasons for readmission } \\
\hline Device complications & N/A & $475(5.3 \%)$ & $270(6.7 \%)$ & $<0.0001$ \\
\hline Wound complications & $\mathrm{N} / \mathrm{A}$ & $172(1.9 \%)$ & $73(1.8 \%)$ & 0.0002 \\
\hline Pulmonary embolism & $30(0.02 \%)$ & * & * & 0.004 \\
\hline Deep venous thrombosis of lower extremity & $1495(1.2 \%)$ & $130(1.4 \%)$ & $79(2.0 \%)$ & 0.33 \\
\hline Venous embolism or thrombosis of other site & $127(0.10 \%)$ & $15(0.17 \%)$ & * & 0.22 \\
\hline Cardiac complications & $60(0.05 \%)$ & * & * & 0.88 \\
\hline Cardiac rhythm conversion & $2405(2.0 \%)$ & $150(1.7 \%)$ & $89(2.2 \%)$ & 0.02 \\
\hline Unspecified septicemia & $7131(5.9 \%)$ & $491(5.5 \%)$ & $265(6.6 \%)$ & 0.01 \\
\hline
\end{tabular}

ORIF open reduction and internal fixation

$S D$ standard deviation

* Value $<10$

$\Pi p$-values of non-operative vs. ORIF vs. arthroplasty as treatment

${ }^{\text {a }}$ Percentages based on initial cohort of subjects 


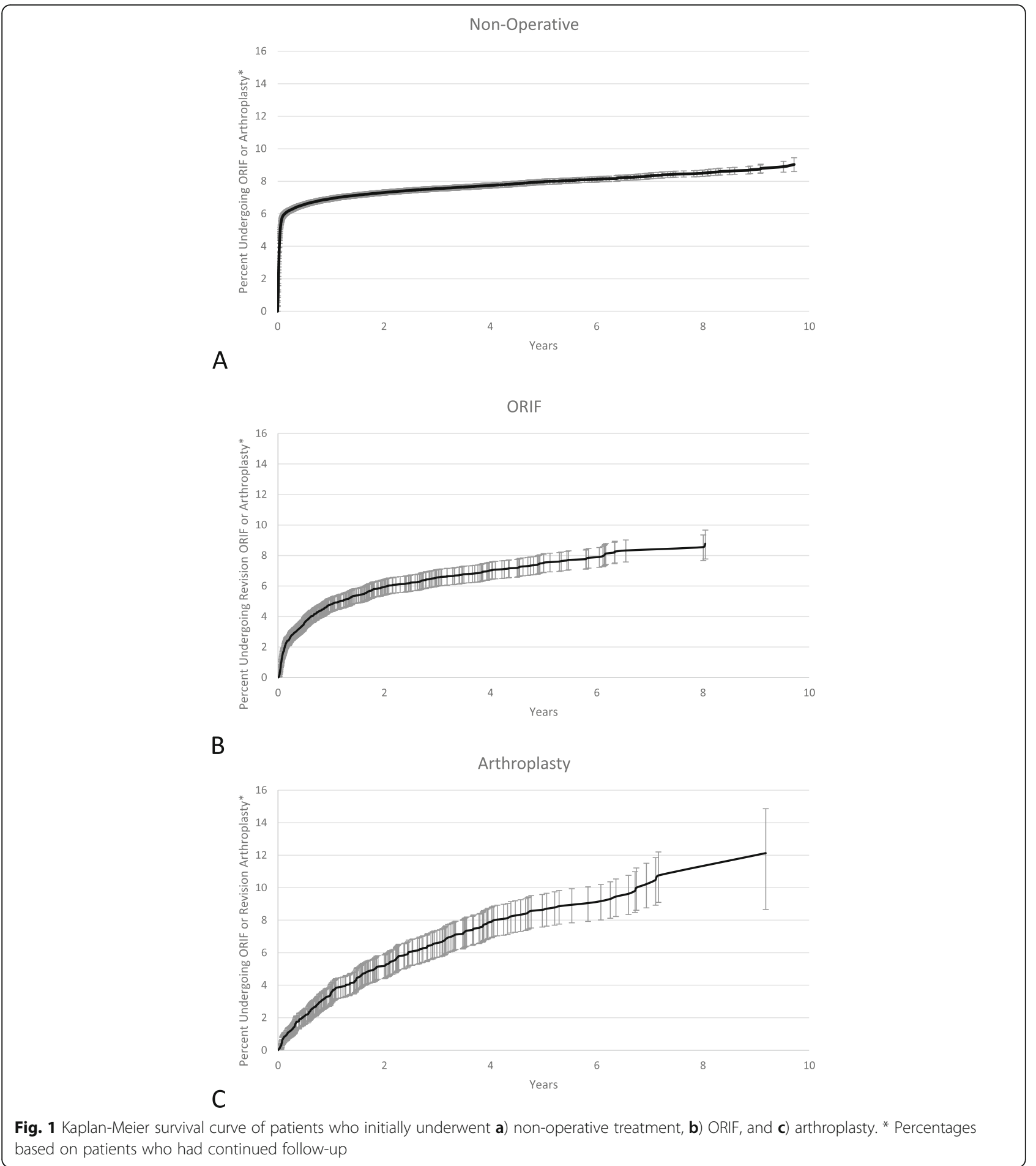

(2006-2009), and Utah (2006-2009) [11]. In our study, rates were slightly higher with $7.9 \%$ of patients having device and wound complications.

There is debate on operative versus non-operative treatment for proximal humeral fractures. Some previous studies have reported that patients undergoing operative treatment are more likely to have complications
$[6,8,9]$ and that no significant difference exists in outcomes after operative and non-operative treatment [5, 7]. Although our study was not designed to assess comparative-effectiveness of operative versus non-operative treatments for proximal humeral fractures, it provides data on complications, readmissions, in-hospital mortality, and time to revision surgery after non-operative 
Table 3 Time to Revision Surgery in Days

\begin{tabular}{|c|c|c|c|c|}
\hline & \multicolumn{3}{|l|}{ Initial Treatment } & \multirow[b]{2}{*}{$p$-value* } \\
\hline & Non-Operative & ORIF & Arthroplasty & \\
\hline \multicolumn{5}{|l|}{ California: } \\
\hline ORIF & $90.7 \pm 284.3 ; 1-2214$ & $358.2 \pm 527.5 ; 4-2209$ & $482.9 \pm 331.7 ; 14-1143$ & $<0.0001$ \\
\hline $\begin{array}{c}\text { Arthroplasty } \\
\text { Mean } \pm \text { SD; range }\end{array}$ & $182.7 \pm 375.9 ; 1-2279$ & $317.1 \pm 370.2 ; 9-1735$ & $599.1 \pm 487.3 ; 1-1847$ & $<0.0001$ \\
\hline \multicolumn{5}{|l|}{ Florida: } \\
\hline ORIF & $139.5 \pm 436.0 ; 1-3476$ & $623.4 \pm 739.2 ; 5-2938$ & $1002.8 \pm 791.5 ; 33-2616$ & $<0.0001$ \\
\hline $\begin{array}{c}\text { Arthroplasty } \\
\text { Mean } \pm \text { SD; range }\end{array}$ & $192.9 \pm 455.2 ; 1-3549$ & $378.6 \pm 523.0 ; 9-2392$ & $588.2 \pm 628.9 ; 9-3354$ & $<0.0001$ \\
\hline \multicolumn{5}{|l|}{ New York: } \\
\hline ORIF & $89.8 \pm 275.5 ; 1-2199$ & $356.5 \pm 491.8 ; 2-1827$ & $606.0 \pm 624.3 ; 23-1668$ & $<0.0001$ \\
\hline $\begin{array}{c}\text { Arthroplasty } \\
\text { Mean } \pm \text { SD; range }\end{array}$ & $145.6 \pm 341.6 ; 1-2330$ & $294.5 \pm 345.3 ; 6-1662$ & $568.0 \pm 533.1 ; 12-1551$ & $<0.0001$ \\
\hline
\end{tabular}

ORIF open reduction and internal fixation

$S D$ standard deviation

* $p$-values of non-operative vs. ORIF vs. arthroplasty as treatment

treatment, ORIF, and arthroplasty. All-cause mortality during in-patient stay was lower for patients initially treated with ORIF (8.8\%), followed by those treated nonoperatively (9.8\%) and with arthroplasty (10.0\%). However, these differences were small in magnitude. It is possible that the lack of difference between in-hospital mortality after non-operative and operative treatment in our study represents a selection bias where patients who are unfit for surgery are frail at baseline. Previous studies have also reported that there was no significant difference in mortality between operative and non-operative treatments [5, 7]. Another study reported mortality rates at 24 months of $7.1 \%$ after non-operative treatment and $11.1 \%$ after hemiarthroplasty [18].

We report data on time to revision surgery after index treatment for proximal humeral fractures. This data is difficult to obtain from large epidemiological studies. In our study, patients who initially received ORIF needed revision ORIF or arthroplasty in $6.6 \%$ of cases, whereas those that initially underwent arthroplasty required revision surgery in $7.2 \%$ of cases. Patients initially undergoing non-operative treatment had subsequent ORIF or arthroplasty in $7.6 \%$ of cases. Previous studies have also found that initial operative treatment after proximal humeral fractures led to an increased number of additional surgeries during follow-up $[5-7,9]$. In our study, the time to revision surgery was shortest for patients initially treated non-operatively followed by those who underwent ORIF and arthroplasty.

Limitations of our study include loss of follow-up of patients who received care in a different state from their index admission. We were unable to ascertain death in the community and hence only in-hospital mortality data is presented. Since administrative databases rely on ICD-9 billing codes, a coding error is possible leading to misclassification. However, we do not have evidence for differential misclassification by treatment group. Data from California was unavailable after 2011 hence longer term survival could not be determined in California. It is possible that in few cases, patients had surgery on the contralateral shoulder for proximal humeral fracture after the index admission. It is not possible to ascertain this from ICD-9 codes and could lead to overestimation of ORIF and arthroplasty procedures during follow-up. Despite these limitations, administrative databases are valuable for providing large-scale information on treatments for patients with proximal humeral fractures.

\section{Conclusions}

This is a large study on patients with proximal humeral fractures in California, Florida, and New York. We report on patient characteristics, treatments, complications, and need for revision surgery. We found that a majority of patients underwent non-operative treatment. Although complications rates were low during the index hospital stay, $5.3 \%$ of patients undergoing ORIF and $6.7 \%$ of patients undergoing arthroplasty required readmission after discharge due to device complications. The incidence of proximal humeral fractures was associated with a relatively high all-cause in-hospital mortality irrespective of the treatment received. Given the recent debate on operative versus non-operative treatment for proximal humeral fractures, our study provides valuable information on the need for revision surgery after initial non-operative and operative treatment. The differences in rates of revision surgery between patients treated non-operatively, with ORIF, and with arthroplasty were small in magnitude. At nine years of follow-up, ORIF had the lowest probability of needing follow-up surgery, and arthroplasty had the highest. 


\section{Supplementary information}

Supplementary information accompanies this paper at https://doi.org/10. 1186/s12891-019-2812-9.

Additional file 1: ICD-9CM diagnosis and procedure codes that were used to ascertain complications. (DOCX $12 \mathrm{~kb}$ )

\section{Abbreviations}

AHRQ: Agency for Healthcare Research and Quality; ANOVA: Analysis of Variance; DVT: Deep Venous Thrombosis; HCUP: Healthcare Cost and Utilization Project; ICD-9CM: International Classification of Diseases, Ninth Revision, Clinical Modification; ORIF: Open Reduction and Internal Fixation; SEDD: State Emergency Department Databases; SID: State Inpatient Databases

\section{Acknowledgements}

Not applicable.

\section{Authors' contributions}

DD: concept and design; drafting of manuscript; acquisition of data; analysis and interpretation of data; final approval of manuscript. HG: analysis and interpretation of data; statistical analysis; final approval of manuscript. AN: analysis and interpretation of data; critical revision of manuscript for intellectual content; final approval of manuscript. NJ: concept and design; acquisition of data; analysis and interpretation of data; critical revision of manuscript for intellectual content; obtaining funding; final approval of manuscript

\section{Funding}

NJ is/was supported by funding from NIAMS 1K23AR059199 and 1U34AR069201.

\section{Availability of data and materials}

The data that support the findings of this study are available from the Healthcare Cost and Utilization Project (HCUP) sponsored by the Agency for Healthcare Research and Quality (AHRQ) but restrictions apply to the availability of these data, which were used under license for the current study, and so are not publicly available. Data are however available from the authors upon reasonable request and with permission of $\mathrm{AHRQ}$.

\section{Ethics approval and consent to participate}

This study is based on secondary analysis of publicly available administrative data. It did not require consent since it was not considered human subjects research.

\section{Consent for publication}

Not applicable.

\section{Competing interests}

The authors declare that they have no competing interests.

\section{Author details}

${ }^{1}$ Vanderbilt University School of Medicine, Vanderbilt University, Nashville, TN, USA. 'Department of Medicine, Brigham and Women's Hospital, Boston, MA, USA. ${ }^{3}$ Department of Orthopaedics, Ohio State University, Columbus, $\mathrm{OH}$, USA. ${ }^{4}$ Department of Physical Medicine and Rehabilitation, Vanderbilt University Medical Center, 2201 Children's Way, Suite 1318, Nashville, TN 37212, USA. ${ }^{5}$ Department of Orthopaedics and Rehabilitation, Vanderbilt University Medical Center, Nashville, TN, USA

Received: 24 January 2019 Accepted: 2 September 2019 Published online: 11 September 2019

\section{References}

1. Kim SH, Szabo RM, Marder RA. Epidemiology of humerus fractures in the United States: nationwide emergency department sample, 2008. Arthritis Care Res (Hoboken). 2012;64(3):407-14.

2. Court-Brown CM, Garg A, McQueen MM. The epidemiology of proximal humeral fractures. Acta Orthop Scand. 2001;72(4):365-71.
3. Lind T, Kroner $K$, Jensen J. The epidemiology of fractures of the proximal humerus. Arch Orthop Trauma Surg. 1989;108(5):285-7.

4. Guy P, Slobogean GP, McCormack RG. Treatment preferences for displaced three- and four-part proximal humerus fractures. J Orthop Trauma. 2010; 24(4):250-4.

5. Rabi S, Evaniew N, Sprague SA, Bhandari M, Slobogean GP. Operative vs non-operative management of displaced proximal humeral fractures in the elderly: a systematic review and meta-analysis of randomized controlled trials. World J Orthop. 2015:6(10):838-46.

6. Song JQ, Deng XF, Wang YM, Wang XB, Li X, Yu B. Operative vs. nonoperative treatment for comminuted proximal humeral fractures in elderly patients: a current meta-analysis. Acta Orthop Traumatol Turc. 2015; 49(4):345-53.

7. Xie L, Ding F, Zhao Z, Chen Y, Xing D. Operative versus non-operative treatment in complex proximal humeral fractures: a meta-analysis of randomized controlled trials. Springerplus. 2015;4:728.

8. Fu T, Xia C, Li Z, Wu H. Surgical versus conservative treatment for displaced proximal humeral fractures in elderly patients: a meta-analysis. Int J Clin Exp Med. 2014;7(12):4607-15

9. Jia Z, Li W, Qin Y, Li H, Wang D, Zhang C, et al. Operative versus nonoperative treatment for complex proximal humeral fractures: a metaanalysis of randomized controlled trials. Orthopedics. 2014;37(6):e543-51.

10. Karl JW, Olson PR, Rosenwasser MP. The epidemiology of upper extremity fractures in the United States, 2009. J Orthop Trauma. 2015:29(8):e242-4.

11. Zhang AL, Schairer WW, Feeley BT. Hospital readmissions after surgical treatment of proximal humerus fractures: is arthroplasty safer than open reduction internal fixation? Clin Orthop Relat Res. 2014;472(8):2317-24.

12. HCUP Databases. Healthcare cost and utilization project (HCUP) [Internet]. www.hcup-us.ahrq.gov/databases.jsp. 2005-2014.

13. Healthcare cost and utilization project (HCUP) [Internet]. www.hcup-us.ahrq gov/sidoverview.jsp. In: HCUP state inpatient Databases (SID); 2005-2014.

14. HCUP State Emergency Department Databases (SEDD). Healthcare cost and utilization project (HCUP) [Internet]. www.hcup-us.ahrq.gov/seddoverview. jsp. 2005-2014.

15. Charlson ME, Pompei $P$, Ales $K L$, MacKenzie CR. A new method of classifying prognostic comorbidity in longitudinal studies: development and validation. J Chronic Dis. 1987:40(5):373-83.

16. Deyo RA, Cherkin DC, Ciol MA. Adapting a clinical comorbidity index for use with ICD-9-CM administrative databases. J Clin Epidemiol. 1992:45(6):613-9.

17. Goel MK, Khanna P, Kishore J. Understanding survival analysis: Kaplan-Meier estimate. Int J Ayurveda Res. 2010;1(4):274-8.

18. Olerud P, Ahrengart L, Ponzer S, Saving J, Tidermark J. Hemiarthroplasty versus nonoperative treatment of displaced 4-part proximal humeral fractures in elderly patients: a randomized controlled trial. J Shoulder Elb Surg. 2011;20(7):1025-33

\section{Publisher's Note}

Springer Nature remains neutral with regard to jurisdictional claims in published maps and institutional affiliations.

\section{Ready to submit your research? Choose BMC and benefit from:}

- fast, convenient online submission

- thorough peer review by experienced researchers in your field

- rapid publication on acceptance

- support for research data, including large and complex data types

- gold Open Access which fosters wider collaboration and increased citations

- maximum visibility for your research: over $100 \mathrm{M}$ website views per year

At BMC, research is always in progress.

Learn more biomedcentral.com/submissions 